\title{
A Review of Personal Data Protection Law in Indonesia
}

\author{
Muhammad Firdaus (201956717) \\ Interdisciplinary Program of Information Security, Graduate School PKNU \\ Pukyong National University, Republic of Korea
}

\begin{abstract}
The importance of protecting personal data issue starts strengthened along with the increasing number of telephone user mobile and internet in Indonesia. Several cases were sticking out, especially those that have a connection with the leak of personal data and leads to fraud or crime, strengthen the discourse on the importance of making legal rules to protect personal data. In Indonesia, the protection of personal data is related to the concept of privacy, which is the idea of safeguarding the integrity and personal dignity. Privacy rights are also an individual ability to determine who is holding their information and how the information is used. Currently, Indonesia's long-awaited comprehensive draft Law on the Protection of Personal Data has been submitted by President Joko Widodo to the Chairperson of the Indonesian House of Representatives on January 24th, 2020. When passed, it will be the first framework legislation on personal data protection in Indonesia. This paper discusses and summarizes the progress of personal data protection based on the law and the regulatory authority in Indonesia. The result shows that there is a lack of explanation of the term data protection authority (DPA) in the final Bill submitted.
\end{abstract}

\section{Introduction}

Indonesia is the largest economy in Southeast Asia and the 16th-largest on the global map according to the rank of gross domestic product (GDP) [1]. Not only in the economic sector, Indonesia, as the fourth most populous country in the world, has enormous potential in the digital ecosystem aspect. Figure 1 shows that there were 338.2 million mobile connections, 175.4 million internet users, and 160.0 million social media users in Indonesia in January 2020 [2]. However, these potentials increase the challenge of personal data protection (PDP). Several cases were sticking out, especially those that have a connection with the leak of personal data and leads to fraud or crime, strengthen the discourse on the importance of making legal rules to protect personal data.

In Indonesia, PDP is related to the concept of privacy, which is the idea of maintain the integrity and personal dignity. Privacy rights are also an individual ability to determine who is holding their information and how the information is used [3]. Personal data collection and dissemination is a violation of privacy due to the right to privacy includes the right to determine whether to provide or not their data. Personal data is an asset or commodity of high economic value [4]. Hence, there is a correlation between the level of trust and protection of data privacy. Unfortunately, the privacy and PDP is not yet regulated in a separate law but is still 
scattered in various legislations

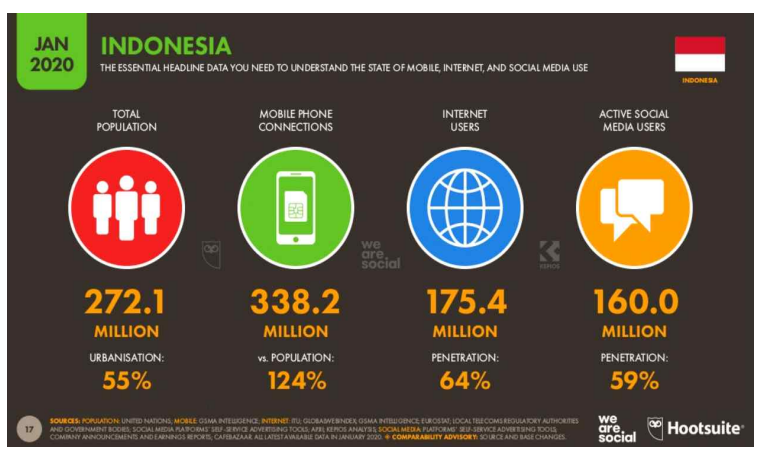

Figure 1. Indonesia's digital data overview 2020 [2]

Starts from 2016, the Indonesian government has initiated the Draft Bill on PDP, which was prepared by the Ministry of Communication and Informatics as the Priority National Legislative Program. Finally, on January 24th, 2020, Indonesia's long-awaited comprehensive draft Law ("the final Bill") has been submitted by President Joko Widodo to the Chairperson of the Indonesian House of Representatives. When passed, the PDP Bill will be the first framework legislation on personal data protection in Indonesia, which has been prepare to be enacted by the House this year [5]. Hence, Indonesia will become the fifth country in ASEAN to implement regulations regarding Personal Data Protection [6].

\section{The Rights of Privacy and Personal Data}

This section provides the definition of personal data and its categories. Then, the rights of the personal data owner will be described refers to Indonesia's PDP final Bill.

\subsection{Personal Data Definition and Categories}

The PDP final draft defines personal data as all data related to an identified and/or identifiable person which can be identified separately or combined with other information, directly or indirectly through electronic and non-electronic systems. This definition mirrors the definition in the European General Data Protection Regulation (GDRP) [7]. There are two types of personal data, as stated below.

a) General personal data: data which consists of full name, gender, citizenship, religion, and/or personal data which combines to enable identification.

b) Specific personal data: personal data that requires special protection, and consists of data relating to health data and information, biometric data, genetic data, life/sexual orientation, political orientation, criminal record, child data, personal financial data, and/or any other data in accordance with the prevailing laws and regulations.

\subsection{The Rights of Personal Data Owner}

The PDP final draft introduces several rights of personal data owner as follows.

a) The right to request access to and/or a copy of personal data correction errors and inaccuracies from the PDC.

b) The right to request termination of personal data processing and/or deletion and/or destruction of personal data, as well as revocation of the processing consent submitted.

c) The right to request whether or not to process personal data through a 
pseudonym mechanism for certain purposes.

d) The right to sue and receive compensation over personal data violations in accordance with the law.

\section{Law and the Regulatory Authority}

The protection of personal data in Indonesia was initially focused on protection from a privacy perspective. Under the Indonesian Constitution, the concept of privacy rights has been recognized and protected as part of the general concept of human rights. With the need to cover the sector yet to be regulated, specifically on internet and electronic transaction-related activities, Law No. 11/2008 on Electronic Information and Transactions as amended by Law No. 19/2016 was passed. Even though most of the provisions of the EIT Law focus on electronic transactions, there is a notable provision that deals with personal data in the EIT Law.

Other than the above legislation, the protection of personal data is also included in several laws and regulations, though most of these laws and regulations only address data protection briefly [8]:

- Law No. 7/1992 regarding Banking as amended by Law No. 10/1998 (the Banking Law);

- Law No. 39/1999 regarding Human Rights;

- Law No. 23/2006 regarding Resident Administration as amended by Law No. 24/2013 (the Resident Law);

- Law No. 36/1999 regarding Telecommunications(Telecommunication Law);
- Law No. 14/2008 regarding Transparency of Public Information;

- Law No. 36/2009 regarding Health (the Health Law);

- Minister of Health Regulation No. 269/Menkes/Per/III.2008 on Medical Records (MoH Regulation 269);

- MoCI Regulation No. 36 of 2014 on the Registration Procedure of Electronic System Operator; and

- MoCI Regulation No. 4 of 2016 on the Information Security Management System (MoCI Regulation 4).

\section{Indonesia's Progress on Privacy and Data Protection}

On 24 January 2020, President Joko Widodo signed the Personal Data Protection (PDP) Bill which is currently being finalized by the Indonesian House of Representatives (DPR). Upon finalization of this PDP Bill, Indonesia will become the fifth country in ASEAN to implement regulations regarding PDP. For the existing PDC, there will be a two-year period before the PDP Bill is fully effective and achieves full compliance.

The PDP Bill regulates a wide range of matters, from types of personal data, stakeholders' rights and obligations, processing and transferring, data protection officer appointments, dispute resolutions, and even administrative and criminal sanctions. It seems safe to say that the scope of this PDP Bill is leaning towards that of the General Data Protection Regulation 2016/679 (GDPR) issued by the European Parliament and Council of the European Union [7].

The PDP Final Draft Law introduces the terms, "Controller" and "Processor" with the same meanings as in the GDPR. This is the first time an Indonesian regulation or law 
has used these terms as the previous Minister of Communications Regulation No. 20 of 2016 on the Protection of Personal Data in Electronic Systems does not use these terms. Under the Final Draft Law, only a natural person can be considered a Personal Data Subject. The Final Draft Law has 72 Articles in 15 chapters covering the following topics.

1. The definition and types of personal data;

2. The rights of data owners;

3. The processing of personal data;

4. The obligations of data controllers and processors when processing personal data;

5. Transferring personal data;

6. Administrative sanctions;

7. Prohibitions against certain uses of personal data;

8. The establishment of behavior guidelines for personal data controllers;

9. The dispute resolution over the use of personal data;

10. International cooperation;

11. The roles of the government and the public; and

It is important to note that the PDP Bill is not the only personal data protection law in existence in Indonesia. Indonesia already has a large number of regulations regarding personal data protection, although they remain sporadic and siloed. This PDP Bill will be the first Indonesian law to provide a comprehensive set of provisions for the protection of personal data, not only via an electronic system but also non-electronically, acknowledging the rights and obligations of the stakeholders involved. The following subsections [6] are the summary of the above topics of the Final PDP draft.

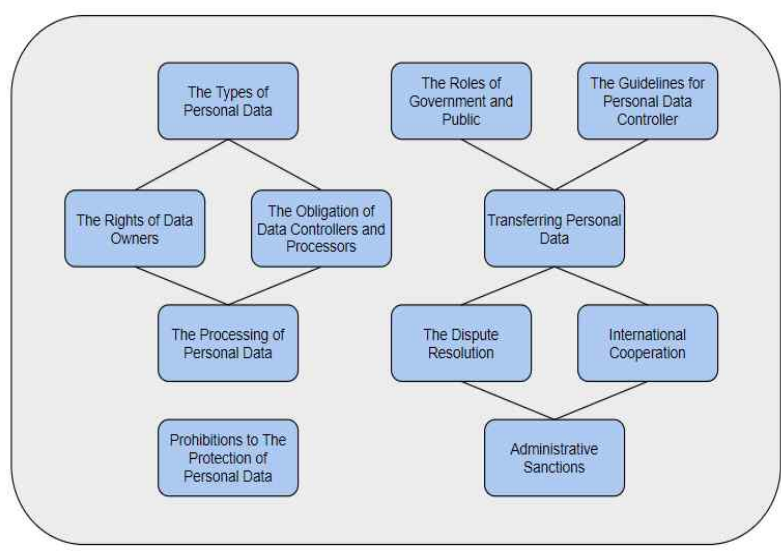

Figure 2. The topics of Indonesia's PDP final draft

\subsection{Personal Data Controller and Processor}

A personal data controller (PDC) is an individual, corporation, public body, business actor, or organization/institution that determines the purpose of and controls the processing of personal data. A PDC is required to ensure the accuracy, completeness, consistency, and security of personal data collected in accordance with statutory provisions. Prior to conducting personal data processing, the PDC must obtain explicit consent from the Personal Data Owner. The consent can be in written form or recorded orally. The following information should be stated in the consent:

a. Personal data processing legality and purpose.

b. The types of personal data that will be managed and their retention period.

c. The rights of the Personal Data Owner (e.g. to update and/or revoke the consent given).

A personal data processor (PDPr) is an individual, corporation, public body, business actor, or organization/institution that processes personal data on behalf of the PDC. The PDPr has legal responsibility for 
any data processing activities, as long as the appointed PDPr conducts the data processing activities in accordance with the instructions from the PDC. Otherwise, the PDPr will bear legal responsibility.

This PDP Bill also states a service level agreement regarding the processing activities that the PDC must achieve, which are as follows:

a. Notifying the Personal Data Owner in the event of any change to the information stated in the consent (as mentioned above) no later than seven days after the change takes place.

b. Updating and/or correcting any errors and/or inaccuracies in personal data no later than 24 hours after the request is received.

c. Processing of personal data termination no later than $3 \times 24$ hours after the request is received.

d. Providing written notification to the Personal Data Owner and Ministry of Communication and Informatics (MoCI) in the event of PDP failure, no later than $3 \times 24$ hours after the failure takes place.

The PDC must protect and ensure the security of the personal data it processes by:

a. Developing and implementing technical measures to protect the personal data from interruptions during processing. For example, the PDC can implement secure storage for personal data storing.

b. Defining the personal data security level during processing as per the nature of and risks involving the personal data. This can be exemplified by ensuring the right to be forgotten within the personal data processing activities.

\subsection{Appointment of a Data Protection Officer}

The PDC and PDPr must appoint an officer to perform the function of protecting personal data in the event of the following:

a. The processing of the personal data is for the benefit of public services.

b. The main activities of the PDC involve a nature, scope, and/or objectives that require regular and systematic monitoring of personal data on a large scale.

c. The main activities of the PDC consist of processing large-scale personal data for specific personal data and/or personal data relating to criminal offenses.

\subsection{Personal Data Transfer}

Personal data transfer from a PDC to another PDC within or outside Indonesia is permitted if consent from the Personal Data Owner has been obtained and the process is in accordance with the PDP Bill. In addition, for transferring data outside the Indonesian legal territory, there are some further requirements that need to be adhered to, such as:

a. The receiving country of the Data Controller or international organization must have a data privacy protection level that is equivalent to or higher than the PDP Bill.

b. There must be an international treaty between Indonesia and the country of the receiving party.

\subsection{Administrative and Criminal Sanctions}


The two types of sanctions for non-compliance with the PDP Bill are as follows:

a. Administrative Sanctions, which will be imposed on business owners in the following forms: a written warning, temporary cessation of processing of personal data, deletion or destruction of personal data, compensation, and/or administrative fines, which will be imposed by the MoCI.

b. Criminal Sanctions. This PDP Bill also states the criminal sanctions for misconduct in personal data privacy. Here are some of the examples:

- Selling/buying personal data;

- Collecting personal data for personal gain;

- Disclosing/using personal data that does not belong to the offender;

- Forging personal data for personal gain or harming others; and

- Operating data visualization tools in the public for identification purposes.

Any violation of the above points may result in imprisonment for up to seven years and/or fines of up to 70 Billion IDR.

\subsection{Ensuring Compliance}

Organizations, especially those that process personal data, will be given a two years before this PDP Bill is fully effective and achieves full compliance. There are some actions that can be taken during this transition period, such as:

a. Review the current Personal Data Protection governance to ensure it covers the end-to-end Data Protection cycle.

b. Review the current contract/consent with customers to include mandatory clauses. c. Review the current business processes that use personal data to ensure that adequate controls have been put in place.

d. Review the third-party governance over personal data management to ensure its compliance with the PDP Bill and main contractor Data Privacy Governance.

e. Review the existing PDP related technology to ensure sufficient security controls.

\section{Discussion}

The most striking aspect of the PDP final Bill is that it fails to include what is generally considered to be the essential element of data privacy law: a separate, specialized (and usually independent) data protection authority (DPA) [9]. Only ten of 143 countries with data privacy laws omit a separate DPA. A concentration of expertise and attention, as well as clear accountability for enforcement, are the main benefits of inclusion of a DPA.

Ministerial enforcement powers are a feature of Indonesia's current data privacy laws and regulations, and have been a conspicuous failure. There has been no Ministerial enforcement in seven years, except that several warnings have been issued. This Bill may also be fated to be ignored, unless it has a DPA dedicated to its enforcement.

There have been quite a few earlier versions of a data privacy Bill drafted by the Indonesian government, but all have involved a specialized DPA. In a recent version, the Public Information Commission was going to act as the DPA, a combination of data privacy responsibilities with Freedom of Information/Right to 
Information (FOI/RTI) responsibilities, which is relatively common (for example, the UK ICO and Australia's OAIC). However, some influential Ministries objected, including on the grounds that Indonesia has too many separate agencies that do not function properly but are very costly to maintain.

\section{VI.Conclusion}

The Personal Data Protection Bill will be the first Indonesian law to provide a comprehensive set of provisions for the protection of personal data, not only via an electronic system but also non-electronically, acknowledging the rights and obligations of the stakeholders involved. This Bill has many features which would, other than for the lack of a DPA, place it among the strongest data privacy laws of the fourteen Asian countries which have such laws. Its GDPR-influenced rights of data owners, and obligations of data controllers and processors would make it one of the strongest data privacy laws. However, in the absence of a specialized Data Protection Authority, the law is likely to be inadequately enforced, with the risk that it will be ignored by both data controllers and data owners. Thus, the international standing of Indonesia's law will not have a 'seat at the table' in international discussions of data privacy policies.

\section{[References]}

[1] Silver, Caleb. (2020). The top 20 economies in the world (March 18, 2020). [Online]: https://www.investopedia.com/insights/worldstop-economies/.

[2] Kemp, Simon. (2020). Digital 2020:Indonesia (February 18, 2020). [Online]: https:// datareportal.com/reports/digital-2020-indonesia.

[3] Gutwirth, S., Poullet, Y., De Hert, P., \&
Leenes, R. (Eds.). (2011). Computers, privacy and data protection: An element of choice. Springer Science \& Business Media.

[4] Rosadi, S. D. (2018). Protecting Privacy On Personal Data In Digital Economic Era: Legal Framework In Indonesia. Brawijaya Law Journal, 5(1), 143-157.

[5] Greenleaf, G. (2020). Indonesia's DP Bill lacks a DPA, despite GDPR similarities. Privacy Laws \& Business International Report. Issue No. 164, April 2020.

[6] Subianto, et al. (2020). Indonesia's Progress on Data Protection. Digital Trust NewsFlash, PwC Digital Services. Issue No.2, May 2020. [Online: https://www.pwc.com/id/en/publication /digital/digital-trust-newsflash-2020-02.pdf.

[7] Regulation, P. (2016). Regulation (EU) 2016/679 of the European Parliament and of the Council. REGULATION (EU), 679, 2016.

[8] Abadi AT. (2019). Data protection and Privacy 2020. Law Business Research 2019. [Online: https://aksetlaw.com/content/uploads/ 2019/09/Data-Protection-Privacy-2020.pdf.

[9] Greenleaf, G. (2014). Asian data privacy laws: trade \& human rights perspectives. OUP Oxford. 